\title{
Una mirada humanista a la educación estética de la sensibilidad humana
}

\section{A humanistic look to the esthetic education of the human sensibility}

Freddy Varona Domínguez

Facultad de Filosofía e Historia, Universidad de La Habana.

fvarona@ffh.uh.cu

\section{Resumen}

Este artículo indaga en los problemas actuales del universo espiritual desde la perspectiva del humanismo, concebido como un sistema de ideas y realizaciones cuyos componentes esenciales son el ser humano, la lucha contra la alienación y el quehacer por el mejoramiento humano. Además, se formula la categoría sensibilidad humana para subrayar la necesidad de emitir respuestas ante los estímulos, la integración de lo afectivo y la razón, así como también la urgencia de que en dicha integración se brinde mayor atención a los sentimientos. Sobre esta base, el artículo despliega algunas ideas sobre la educación estética de la sensibilidad humana con el objetivo de destacar su potencial desalienante y de mejoramiento humano.

Palabras clave: humanismo, estética, educación, sensibilidad.

\section{Abstract}

This article is a theoretic study that departs from the need to find innovative solutions to the present problems of the spiritual universe. It proposes to do so from the perspective of humanism, conceived as a system of ideas and realizations, whose essential components are the human being like main value, the fight against the alienation and the task for the human improvement. In addition, we expose the concept of human sensibility to emphasize the need of articulating answers to the stimuli, the integration of affection and reason, and the need to pay more attention to feelings in such integration. The article develops some ideas on the esthetic education of the human sensibility in order to highlighting its contrary essence in relation to alienation and in favor of human improvement.

Keywords: Humanism, Aesthetics, Education, Sensibility. 


\section{Introducción ${ }^{1}$}

Pensar la educación es siempre una tarea de suma complejidad. Esto se debe a muchos factores, pero sobre todo a uno: está esencialmente relacionada con las características, contradicciones, tareas y exigencias del presente, en el cual convergen el pasado y el futuro en cuanto al deber ser, los ideales y la realización de ambos.

La adaptación de la concepción de la educación a las exigencias actuales y del futuro cercano, así como del quehacer educacional, son grandes desafíos que hoy tiene la humanidad. Estos refieren a los modos de alcanzar niveles superiores en su esencia dialogadora, crítica, emancipadora (Díaz 2), consolidar la conciencia planetaria, fortalecer el respeto a la diversidad, incrementar la manifestación contra las ideas y los hechos antihumanos, y por sobre todo acrecentar el enriquecimiento del universo espiritual.

Amerita una acotación: en este texto la categoría universo espiritual se refiere a la vida espiritual de la sociedad, es decir, la producción de ideas, teorías, sentimientos, valores, creencias, ideales, así como su difusión, intercambio, consumo, conservación, destrucción. Incluye las obras de la ciencia, la religión, la filosofía, la política, la literatura, el arte, la moral, la estética y sus relaciones con las necesidades, los intereses y los fines sociales e individuales.

Es posible que se considere que no urge pensar en el enriquecimiento de dicho universo y, mucho menos en la educación estética, en un contexto donde existen tantos problemas que agobian a la humanidad en la segunda década del siglo xxi e incluso ponen en riesgo la supervivencia del planeta. No hay duda de que algunos son básicos -la alimentación, el empleo laboral, la vivienda y la salud- y es preciso priorizar su solución, pero la vida humana posee otras dimensiones que no se debiesen ignorar, antes bien, en determinadas circunstancias, habría que atenderlas con mayor esmero. Tal es el caso del enriquecimiento del universo espiritual.

Hoy la existencia e intensificación del "egoísmo, la violencia y la mezquindad espiritual parecen socavar la bondad de nuestra vida colectiva” (Goleman 8). Junto con ello, el aumento de la agresividad y otros problemas emocionales (10) se hacen evidentes: la industrialización de las relaciones sentimentales-sexuales mediante los encuentros digitales - una especie de mercado de relaciones sexuales rápidas

1 El antecedente oficial del presente trabajo es el proyecto de investigación CAPES-MES, Brasil-Cuba, número 055-88 (2008-2010), entre la Universidad Federal de Minas Gerais y la Universidad de Holguín, titulado "Complejidad, transdisciplinariedad y educación superior" donde el autor profundizó en la educación estética en las universidades y sus nexos con la cultura. Sin embargo, el estudio de las relaciones humanismo-cultura-estética en el pensamiento filosófico occidental lo comenzó en los años ochenta, cuyos resultados se han expuesto en eventos científicos nacionales e internacionales. Entre sus publicaciones destaca Cultura, cine y ser humano: una mirada a Humberto Solás, La Habana: Ciencias Sociales, 2014. En la escritura de este artículo influyóel llamado realizado por el papa Francisco en Cuba durante la misa oficiada en la ciudad de Holguín el 21 de septiembre de 2015. Allí motivó a pensar más en el embellecimiento del alma con la amistad, el perdón, la humildad y el amor, así como en el papel que estos valores tienen para el desarrollo de la familia y la solución de muchos problemas sociales de hoy. 
(Lardellier 79)-; el incremento de parejas flexibles y efímeras (Venegas 576); la atención del cuerpo como un accesorio para moldear en un marco de belleza donde no importa la salud (Espinal, Estrada y Pérez 190), sino la moda (Retana 326). Al decir de Bodei: "la miseria de lo insignificante; el placer regresivo de ver volver lo que ya se conoce y, por ello, da seguridad; la martilleante repetición de lo siempre igual; el triunfo de la banalidad y de la cháchara; el aturdimiento mental y emotivo; [...] la inutilidad de tantos intentos de creación de nuevas formas de expresión" (La forma 157); y si no bastara: "la indiferencia recíproca" (Geometría 6). Tales problemas son del universo espiritual.

Algunos de ellos existen en Cuba y cada vez con mayor presencia. Uno de los más inquietantes es la indiferencia, que ya obliga a pensar cómo detenerla y revertirla en su contrario. La educación se muestra en este panorama como un instrumento de extraordinario valor; pero hay que abordarla con mayor amplitud mental, con deseo innovador (orientado a hallar nuevas posibilidades teóricas y prácticas) y con intenciones integradoras. Por ende, en el presente texto se busca respuestas no solo en el marco de la razón, sino también en el afectivo, se atiende con optimismo la educación estética y se emplea creativamente la categoría sensibilidad humana.

Sobre esa base, en este trabajo se estudia la educación estética de la sensibilidad humana desde la perspectiva del humanismo, para destacar su esencia desalienante junto con su capacidad de mejoramiento humano, potencialmente utilizable para resolver algunos problemas actuales del universo espiritual, en específico la indiferencia. Contiene reflexiones de carácter filosófico, muchas de ella apoyadas en la situación concreta de Cuba. Se emplearon los métodos siguientes: análisis-síntesis, inducción-deducción, histórico-lógico, conjugación de lo universal y lo particular y comparación (de ideas, principios, tendencias, objetivos). Está estructurado en los siguientes acápites: "Puntualización teórica del humanismo"; "En torno a la educación estética"; "Distinción teórica entre sensibilidad y sensibilidad humana" y "La educación estética de la sensibilidad humana vista desde el humanismo".

\section{Puntualización teórica del humanismo}

Más de un autor afirma que la palabra humanismo fue puesta en circulación por el pedagogo alemán Friedrich Niethammer para insistir en la supremacía educativa de los clásicos de la cultura greco-latina, en relación con la ciencia y la técnica modernas (Rodríguez 13). A partir de ello se sostienen criterios como los siguientes: "el concepto de humanismo se refiere de un modo expreso a la educación y la cultura de la Antigüedad" (Jaeger 300) y es "la corriente cultural que nos viene de Grecia y Roma a través del Renacimiento" (Vitier 105).

Varios estudiosos, cuando vinculan humanismo y Renacimiento, lo denominan humanismo renacentista y destacan el papel central que en ese entonces se le otorgó a los 
humanos en el quehacer filosófico, artístico, literario, político, educacional, así como la exaltación de la libertad, la dignidad y el conocimiento de la naturaleza. De este modo, el humanismo se comprende como un movimiento cultural, una nueva mirada a los humanos y sus valores (Toffannin 514), una manera diferente de pensar, una corriente de pensamiento o una actitud del espíritu de la época renacentista (Martins 99).

Con el paso del tiempo la concepción del humanismo ha variado y han surgido diversos tipos (Varona 26-9), pero, por lo general, en todos está presente la importancia de los humanos y su beneficio, así como la confianza en sus capacidades para avanzar en todos los sentidos. Una muestra de ello es cuando se le define en tanto "un conjunto de ideas que destacan la dignidad de la persona, la preocupación por su desarrollo armónico y la lucha por crear condiciones favorables al logro de tales fines" (García 118). Ahora bien, lo verdaderamente relevante y esencial es su carácter desalienante (Guadarrama 3) y de mejoramiento humano.

El humanismo constituye un sistema de ideas y realizaciones cuyos componentes esenciales e imprescindibles son los seres humanos como valor principal y centro de atención de cualquier idea o acción, la lucha contra todo tipo de alienación, y el mejoramiento humano. Siempre en su fundamento existe algún tipo de concepción acerca del ser humano.

En las concepciones acerca de los humanos sobresale que se hace de una especificidad el centro y se toma como lo esencial y definitorio. Tal es el caso de la razón (Descartes 160), los sentimientos (Rousseau 165), el conjunto de relaciones sociales (Marx 9), la capacidad de pensar en Dios (Ruiz 76), el nexo biosocial (Minkevicius 144), la imaginación (Lapoujade 193). Con esta variante, propia de la modernidad y del pensamiento simplificador, la humanidad logró resultados innegables, sin embargo, el desarrollo actual de los conocimientos científicos exige otro modo de pensar: el pensamiento complejo que, entre otros rasgos, es integrador (Morin, La cabeza 125) y responde a los desafíos de dichos conocimientos (Maldonado 13).

El pensamiento complejo es el fundamento de la concepción de humanismo empleada en este texto, desde el cual se comprende al ser humano como un todo complejo cuya esencia está en la bipolarización de caracteres antagónicos (Morin, Los siete saberes 35). A su luz, las facultades y características de los humanos se conciben de forma integrada. Por ello, en los cimientos de este escrito se encuentra la conjugación de la razón y los sentimientos. Sin embargo, a estos últimos hay que atenderlos más si se quiere lograr el equilibrio de ambos, no como un fin, sino para fortalecer las capacidades de los humanos y avanzar en su desalienación y mejoramiento.

La alienación consiste en todo estado de oposición a los humanos (vistos individual o grupalmente), donde se conjugan relaciones objetivas y subjetivas, conscientes e inconscientes, espontáneas y forzadas, materiales y espirituales, psico-bio-socioculturales, entre otras; es dialéctica, histórica-concreta y su manifestación puede ser muy variada (cultural, económica, social), pero siempre es de opresión, impedimento, degeneración, enturbiamiento, discriminación. 
No se debe perder de vista que la alienación cambia continuamente sus formas y que no cesan de aparecer otras nuevas. El humanismo es esencialmente su antítesis; de ahí su poder desalienante, que es mayor cuando no se limita a la teoría, sino que abarca también la práctica. Para ello es decisivo el reconocimiento que los humanos hagan de sus facultades y capacidad para transformar el mundo en su beneficio, a partir de sus potencialidades y espíritu creador. No obstante, con el carácter desalienante el humanismo no está completo: precisa conjugarse con el mejoramiento humano, el cual debe corresponder a las exigencias y desafíos del momento histórico presente y del futuro, así se puede lograr en cada individuo y en la sociedad completa, las cualidades superiores históricamente alcanzables.

Por lo anterior, el quehacer teórico y práctico contra la alienación y por el mejoramiento humano son procesos dinámicos a los cuales no se les puede poner un límite final, es decir, una meta a la que se llega una vez. Esta visión condiciona que el humanismo no pierda vigencia y que exija constancia y creatividad. En este sentido, la educación posee suma relevancia.

\section{En torno a la educación estética}

La educación es imprescindible para llevar adelante el propósito de enriquecer el universo espiritual y, por ende, atacar la indolencia ante las ideas y los hechos que engendran odio, discriminación y conducen a limitar, impedir o desdeñar el mejoramiento humano. Hoy urge tomar conciencia de las novedades y retos que tiene ante sí la labor educacional y los educadores: optimizar la transmisión y uso de los conocimientos científicos, propiciar y estimular el desarrollo humano multilateral (físico y espiritual); inculcar la disposición de atacar y exterminar las iniquidades, cuidar el planeta y "afianzar, preservar y desarrollar lo propio, para encontrar nuestro ser esencial e insertarnos en la cultura universal con derecho soberano” (Pupo 44), en suma, construir un futuro mejor.

En todo ese entramado de tareas y objetivos, la educación estética tiene un sitio específico. En torno a ella han existido diversas opiniones desde que el filósofo alemán Alexander Gottlieb Baumgartem (1714-1762) comenzó a utilizar dicha palabra. Entre aquellas destaca las que la limita al arte y lo artístico, como Hegel (27), Sánchez Vásquez (51) y Jacques Rancière. Para este consiste en "un régimen específico de visibilidad y de inteligibilidad del arte, que se inscribe en una reconfiguración de las categorías de la experiencia sensible y de su interpretación" ("Pensar entre" 1), la ve "como régimen de funcionamiento del arte y como matriz discursiva, como forma de identificación de lo propio del arte y como redistribución de las relaciones entre las formas de la experiencia sensible" (El malestar 25). También sobresale el criterio que la asocia a la sensibilidad y los sentimientos (Bayer 183; Audi 320; De la Fuente 3), los cuales, por lo general, son ubicados en los fundamentos de la concepción. 
No está de más señalar que con frecuencia la estética es igualada a la belleza y lo bello, lo cual no es un error, en tanto están en su fundamento, pero sí constituye un reduccionismo, porque en dicho fundamento están asimismo la fealdad y lo feo (sus contrarios dialécticos), así como las relaciones que se establecen entre ambas partes. Además, sobre esta base, en la estética están incluidos más nexos, como son, lo maravilloso y lo grotesco, lo sublime y lo bajo, lo elegante y lo cursi. En ella, lo verdaderamente básico y esencial es la sensibilidad estética, que tiene lugar en dichos vínculos y debido a ellos. Este todo recorre las diversas relaciones humanas.

Si la estética, en tanto saber específico, se ha identificado con la filosofía del arte, y lo estético y lo artístico se han aproximado tanto que casi se han llegado a fundir, es de imaginar que la educación estética se ha igualado a la educación artística o a la apreciación artística, incluso ha sido reducida a una estrategia sociocultural de instituciones educativas y culturales. También se ha vinculado exclusivamente al empleo de la belleza en la docencia o a las llamadas actividades culturales, las cuales con frecuencia se restringen al estudio de las tradiciones locales, al encuentro con personas vinculadas al arte y la literatura, al quehacer artístico y literario o a la lectura y observación de tales obras que, ciertamente, tienen un lugar especial en dicha educación, ya sea en cuanto a la participación activa en su creación o desempeño, como en el trabajo teórico (Larmin 28), pero no se limita a ellas.

La educación estética puede concebirse como el despliegue de la capacidad de percepción y disfrute, la consolidación de posiciones, la formación de valores y la estimulación de creatividad, en todos estos casos, de carácter estético. Esencialmente consiste en la incentivación, el desarrollo y el moldeamiento de la sensibilidad estética.

\section{Distinción teórica entre sensibilidad y sensibilidad humana}

La palabra sensibilidad tiene más de un significado. Uno de ellos refiere a la facultad de sentir, propia de los seres vivos, que en el caso de los humanos "es siempre una conquista sobre la naturaleza y no algo dado inmediatamente" (Sánchez Vázquez 48), porque sus sentidos fueron dejando de ser estrictamente biológicos en la misma medida que en la actividad, sobre todo en la práctica, desarrollaron propiedades humanas y, de hecho, se enriqueció la conciencia sensible.

Otra de sus acepciones es la cualidad propia de cuanto tiene la facultad de sentir, de experimentar sensaciones, que en los humanos pueden ser físicas o morales y producen sentimientos; en este caso, desde la perspectiva en que se observe, puede hablarse de sensibilidad política, ecológica y, también, estética. Acerca de esta última Adolfo Sánchez Vázquez afirma que es tanto una forma específica de la sensibilidad propia de los humanos, como "una forma superior de ella, en cuanto que expresa en toda su riqueza y plenitud la verdadera relación humana con el objeto como confirmación de las fuerzas esencialmente humanas en él objetivadas" (50). Según este 
autor, en dicha superioridad es crucial que el objeto estético solo existe en las formas concreto-sensibles y solo así se ofrece a los sentidos. Sin embargo, esto se da siempre con una significación ideológica y afectiva, por ende, en la relación de los humanos (en tanto sujetos) con el objeto están integrados lo sensible y lo intelectual.

De dicha posición se desprende la inconsistencia del criterio que señala que los valores artísticos y los estéticos son indefinibles. Además, retomando al autor Fabelo Corzo ("Por una estética" 100), es necesario atender la legitimación de cuanto tenga que ver con la estética y recalcar que en este marco no ha de reconocerse lo que atente contra la humanidad. Hoy urge una teoría estética que porte (junto a los asuntos que históricamente la han formado) el interés por la vida y que, en esta misma medida, su centro de atención sea el enriquecimiento espiritual, el mejoramiento humano y la lucha contra todo tipo de alienación.

Entre los significados de la palabra sensibilidad también puede hallarse el que refiere la tendencia natural humana a dejarse llevar por la compasión, la piedad, la ternura, así como el comportamiento que de allí se desprende. A su vez, la palabra de marras se emplea para hacer referencia a la propiedad de los seres humanos para manifestarse de alguna manera: atracción o rechazo, aun cuando los estímulos sean sumamente pequeños y aparentemente insignificantes.

Sobre esa base toma consistencia la categoría sensibilidad humana. Con ella se quiere subrayar lo siguiente: i) urge darle mayor atención a la integración de los sentimientos y la razón; ii) en dicha integración, para logar equilibrio, se debe priorizar lo afectivo, sobre todo los sentimientos; iii) todos los estímulos son importantes, aunque sean mínimos; iv) ante los estímulos debe haber respuestas y atenderse; v) el adjetivo humana significa no solo que pertenece a los humanos, sino que contiene una finalidad humanamente constructiva verbal o de acción, por lo cual es antítesis de la indiferencia y la pasividad; vi) no bastan la piedad y la ternura, es imprescindible la solución de los problemas; vii) su espíritu es marcadamente tolerante y comprensivo para no desencadenar violencia, sino solidaridad y ayuda.

Esta concepción de sensibilidad humana tiene antecedentes. Uno de ellos es el concepto razón poética de la filósofa española María Zambrano (20), quien lo sostuvo para referir la integración de la razón y los sentimientos en tanto vía para enfrentar los problemas del mundo que le tocó vivir. Entre ambas concepciones hay un punto común: la mencionada integración, pero en la sensibilidad humana la pretensión integradora se encamina a destacar la importancia de todo estímulo y de las reacciones con la finalidad de acabar con la indiferencia y potenciar el activismo social (no solo político).

Cercano a la sensibilidad humana está la concepción de inteligencia emocional del autor Daniel Goleman. Esta se encuentra basada en el vínculo entre los sentimientos, el carácter y los impulsos morales, así como en la relación entre las actitudes éticas y las capacidades emocionales subyacentes; trata de armonizar la razón y los impulsos emocionales y para ello enfatiza la utilización inteligente de las emociones (Goleman 
41); tienen un sitio significativo el entusiasmo, la perseverancia, la capacidad para automotivarse y, sobre todo, el autocontrol (Goleman 302).

El espíritu integracionista tiene lugar, asimismo, en otras comprensiones, como la que sostienen Arias y Lemos en torno a la inteligencia espiritual, donde se conjugan lo cognitivo, lo afectivo y lo conductual $(12,205)$. Esta idea se aviene con la del autor R. Bodei con respecto a que los nexos entre los conceptos razón y pasión deben dejar de aprehenderse como lucha "entre lógica y ausencia de lógica", incluso "se podrá interpretar esta relación, si acaso, como conflictividad entre dos lógicas complementarias" (Geometría 4). Otros autores han acentuado la correspondencia entre las emociones y la razón, así como la posibilidad y el beneficio de conjugarlas (Viegas 10-1), donde, a su vez, se hace hincapié en la actividad.

Cercana a la concepción que se defiende en este trabajo es la idea de sensibilidad de entorno (Wagensber 10), la cual recalca la relación entre el individuo, su libertad y el entorno -sobre todo social- apoyado en el conocimiento de las condiciones objetivas y el correspondiente comportamiento humano como ser complejo. Por eso alude momentos importantes: la intencionalidad, la construcción, la creatividad, la flexibilidad, entre otras, que siempre responden a principios, propósitos, ideales, de corte moral, social, político, económico, junto con referir a las relaciones entre las condiciones previsiblemente imprevisibles y las acciones humanas. Pero esta no tiene como propósito atacar la indiferencia y la insensibilidad.

Otras de las concepciones sobre la sensibilidad humana es la del autor Beltrán Anglada, quien la despliega desde la psicología y la concibe en cuatro tipos: la mental, la emocional, la física y la religiosa. Anglada la ve apta para todos los humanos, pero solo utilizable por quienes poseen una mente muy desarrollada y un corazón abierto a las necesidades sociales.

Dichas teorías estudiadas son valiosas de diversas formas porque, en el fondo, consisten en una búsqueda de soluciones a los problemas de la humanidad. Uno de ellos es la eliminación de las disyunciones innecesarias y el avance de la integración; esto es en sus diversas manifestaciones, como entre lo afectivo y lo racional (Morin, Los siete saberes 17). Entre estos últimos urge lograr equilibrio; ahora bien, para lograrlo es necesario priorizar los sentimientos y destacarlos, porque en la actualidad prevalece lo racional. Hace falta acentuar la educación de la sensibilidad, que ya enfatizaba F. Schiller en el siglo XVII "no tan solo porque es un medio de dar eficacia en la vida a los progresos del saber, sino también porque coadyuva a la mejora del propio conocimiento" (43) y avanzar en la sensibilidad humana.

Allí es donde estriba la relevancia de la educación estética, que no consiste en imponer modelos de gustos, deseos y preferencias (Valdés 76), sino en estimular el componente sensible de los humanos y conjugarlo con lo racional en mayor equidad $\mathrm{y}$, desde ese nivel, desplegar la sensibilidad humana, que en el marco estético (valga el énfasis) se desenvuelve con los nexos belleza-fealdad como núcleo, con las especificidades de cada individuo y su entorno. 


\section{La educación estética de la sensibilidad humana vista desde el humanismo}

La educación estética de la sensibilidad humana puede entenderse como un sistema de acciones estéticas encaminadas a actuar sobre la conjugación de lo afectivo y lo racional a fin de activar a los seres humanos en el enfrentamiento a la indolencia. Al atenderla desde la perspectiva del humanismo se persigue destacar su esencia desalienante junto con su capacidad de mejoramiento humano, para resolver, aunque sea en alguna medida, algunos problemas actuales del universo espiritual, en específico, la indiferencia y con ella la autolimitación. Desde esta perspectiva se observa, de manera sistémica, la factibilidad y fundamentos de dicha educación, sus principios, propósitos y estrategias.

Factibilidad de la educación estética de la sensibilidad humana. Aunque más arriba se han expuesto algunas ideas acerca de la educación estética, no está de más insistir en que es posible realizarla, aun cuando en el mundo de hoy se abren paso continuamente la diversidad, lo individual y lo específico. Su factibilidad se debe al cambio que ella misma ha tenido en sus objetivos básicos: no imponer criterios, sino conducir a los humanos a descubrir su sensibilidad estética y lo que la estimula. Por tanto son fundamentales las especificidades individuales, guiar a los individuos a captar la vida y a disfrutarla en una dimensión espiritual mayor.

Por otro lado, amerita enfatizar que la educación estética, al igual que la educación en sentido general, se extiende a lo largo de toda la vida y la lleva adelante toda la sociedad a través de la familia, los amigos, los compañeros, los vecinos, las llamadas instituciones culturales, las escuelas en sus diferentes niveles y, entre otros, los medios de comunicación masiva. De estos, vale destacar su dependencia de la política (si esta favorece la educación, los resultados pueden ser provechosos) y su amplitud, variedad y alcance, que favorecen la educación cuando está a su servicio. Hoy también procede hablar de los medios digitales y las redes sociales.

En Cuba, la realización de una educación estética de la sensibilidad humana puede desplegarse en las escuelas y las llamadas instituciones culturales (teatros, museos, bibliotecas, entre otras), donde sobresale el trabajo de los promotores culturales y otros activistas. En ambos casos se posee un sistema educativo organizado, con profesionales generalmente bien preparados para este tipo de trabajo y con deseos de hacerlo, tanto en la docencia, como fuera de ella.

Este tipo de educación debe tener como primer objetivo llevar adelante la obra de educar estéticamente la sensibilidad humana: una faena difícil y, además, que exige mucho optimismo. Una vez que esté en pie la intención, se puede llevar a cabo con el empleo de la capacidad estética del entorno sociocultural y natural: la flora, la fauna y las actividades sociales e individuales, pues abren múltiples caminos y modos para su realización, así como el arte y la literatura. Los efectos más grandes y profundos pueden alcanzarse si existe un proceso estético-educativo planificado, con un programa 
contendiente de un sistema de acciones y control de los resultados, que deseche la improvisación y el voluntarismo (Estévez, La educación estética 51) y que aproveche al máximo "el grado de sensibilidad estética que posea el sujeto de la recepción [...] para la conformación del juicio estético" (32).

\section{Principios de la educación estética de la sensibilidad humana}

Algunos de ellos son:

1. El punto de inicio está en las especificidades de cada ser humano (Valdés 76), lo cual no debe verse como desestimación de la influencia sobre la personalidad ajena.

2. Incluir en su realización todo el espectro sociocultural y natural. Este principio impide la absolutización del arte y la literatura en tanto núcleo de esta educación y que se limite a ellos, aunque no los excluye; además, favorece que junto a los maestros y los instructores de arte participen, como educadores, otros miembros de la sociedad, ya sea desde el colectivo laboral, las instituciones políticas, las organizaciones sociales (Estévez, La alternativa estética 20) y la familia. De este modo no es pertinente la identificación de la educación estética con la educación artística (21).

3. No tiene que realizarse mediante una asignatura que se llame Educación estética (54), ya que el efecto educativo deseado (despertar la sensibilidad y eliminar la indiferencia) puede alcanzarse no solo a través del trabajo docente, sino por diversas vías. No obstante, es recomendable que exista una asignatura centrada en estos objetivos.

4. No limitarse al empleo de un único enfoque teórico y metodológico.

5. Debe presentar un carácter perenne y sistémico, lo cual presupone que se realice mediante la acción coordinada de toda la sociedad y abarque las distintas esferas de la actividad humana (Montero 33).

6. Hay que tener presente que es un proceso complejo y, por tanto, debe contar con un programa científicamente fundamentado, el cual postule que el gusto estético no es un resultado casual, ni solamente individual, es decir, que no niega, ni relega a planos inferiores las acciones espontáneas ni el desarrollo que cada quien le brinde a sus gustos estéticos y artísticos.

7. Debe velar por los sentimientos de manera especial. Esto es atender a su calidad desde la perspectiva estética (que ha de expresarse a través de la intensidad de la percepción emocional y el disfrute estético) y cuidar su relación con la sociedad (necesidades, intereses, fines).

8. Estimular el desarrollo de las necesidades y los intereses que fortalecen los valores estéticos con especial atención a la identidad cultural, sin desdeñar las otras culturas.

9. Enfrentamiento a los pseudovalores estéticos, mucho más si son raigalmente ajenos a la identidad cultural propia. Este asunto debe entenderse como un principio a 
seguir, pero no debe confundirse con un cierre a lo nuevo, lo foráneo o lo universal. En este caso la grandeza está en la capacidad de asimilar lo humanamente provechoso, adaptándolo a cada cultura.

\section{Propósitos de la educación estética de la sensibilidad humana}

Entre ellos están:

1. Contribuir a la formación del gusto estético y del artístico para, mediante ellos, favorecer el desarrollo de la creatividad, la capacidad para apreciar el arte y discernir lo feo y lo bello, lo bajo y lo elevado, lo cómico y lo trágico, lo grotesco y lo sublime. Además, hace falta que la creatividad se vuelque a conquistar el interés de los individuos, sobre todo por los valores con los que se atenta contra la indiferencia.

2. Construir el ideal estético porque en tanto eje transversal atraviesa la vida espiritual y así está presente en todas las variantes de la educación y en la actividad humana, por lo cual, a su vez, funciona como un ente que cohesiona la formación integral.

3. Preparar a los individuos y a las grandes masas para el consumo de los productos culturales (Estévez, La alternativa estética 4) a partir de la incentivación de la fantasía, la imaginación y la creatividad, así como del incremento del interés por la creación artística.

4. Conservar y desarrollar la identidad, tanto la estética como la cultural y desde este punto coadyuvar a la armonía de las relaciones sociales mediante la interacción empática entre los individuos, entre ellos y la naturaleza, y entre ellos y la sociedad. No casualmente con dicha educación se intenta formar estéticamente una personalidad cuya característica principal sea la posesión de motivaciones no exclusivamente estéticas, sino también éticas y ecológicas, porque "no es coherente quien, habiendo desarrollado cierto sentido de la belleza, no luche porque ella impere en su entorno natural y social (en su comunidad); o quien, siendo capaz de apreciar la belleza del paisaje, de la flora y de la fauna, no sienta un profundo amor y respeto por la naturaleza" (Estévez 7). Cada individuo no siempre se llega a este nivel de interrelación, entre otros factores, por las características individuales. Sin embargo, lo cierto es que quien ame enriquecer su universo espiritual, por lo general expande sus valores donde quiera que esté.

5. Actuar sobre la sensibilidad de cada individuo a fin de que lo estético se impregne en sus proyectos. El cambio cualitativo no ocurre verdaderamente en la sociedad si los individuos no se sienten identificados con el entorno social.

6. Contribuir a la formación integral de hombres y mujeres, así como de profesionales que se caractericen por su sentido creador y su sensibilidad humana. En esto es vital que se logre aguzar y ampliar el espectro sensitivo mediante la potenciación de las capacidades estético-perceptivas y la orientación coherente del gusto esté- 
tico (Estévez 32) y que se estimule la atención por la belleza para enriquecer los sentimientos e incentivar la sensibilidad, no solo con fines estéticos individuales, sino para participar en el perfeccionamiento de la sociedad.

7. Lograr que en todas las actividades humanas exista belleza: si no se piensa en ella, el resultado del trabajo no puede ser bello (Montero 32). En su universo espiritual, los seres humanos poseen un componente estético que se conforma y despliega ligado a su sensibilidad, lo cual influye en toda su vida e incluso es decisivo en sus manifestaciones y en los rumbos que toma. La dimensión estética no es únicamente una meta a lograr, es asimismo un punto de partida que se debe atender con esmero, porque el asunto está en "formar una nueva sensibilidad, de desarrollar una apreciación más variada y profunda de la cultura, que contribuya a una felicidad personal y colectiva y a una más rica definición de los rasgos de la nacionalidad" (Silva 3). La atención por la belleza no significa que se deje de tener en cuenta la fealdad y lo negativo; a la luz del humanismo se les reconoce su espacio y se entiende que su existencia parte de que los humanos son perfectibles, además, se destaca la importancia de captar el espíritu contestatario y de perfeccionamiento que portan para actuar en correspondencia.

\section{Estrategias de la educación estética de la sensibilidad humana}

Entre ellas están:

1. Si se mira críticamente la situación de la educación estética en Cuba, se llega a entender que debe implementarse un trabajo estratégico creativo y extensivo para que se incremente la cantidad de especialistas que se dedican a profundizar con sistematicidad en los problemas teóricos y prácticos de la educación estética -no confundirlos con estudiosos y expertos de arte, literatura o estética filosófica-. La educación estética se imparte en contadas carreras universitarias y no son pocos los estudiantes que exhiben deseo de eliminarla o desinterés en ella.

2. Es necesario destacar su papel educativo y social para incentivar su desarrollo. No es una casualidad que en las bibliotecas escolares y públicas sea escasa la literatura especializada en educación estética, en su mayoría desactualizada. Además, debido a que con frecuencia se iguala a la educación artística es notorio que su conocimiento no tiene la profundidad que debiera, lo que "se manifiesta en confusiones conceptuales; poco dominio de las categorías de la estética y un desconocimiento (casi generalizado) de la teoría de la educación estética y la educación artística y del papel específico de ambas en la formación integral de los estudiantes" (Estévez, La educación estética 77).

3. Fortalecer sus vínculos con la vida, lo cual debe repercutir favorablemente en el desarrollo de la capacidad de percepción estética y en la formación en todos los miembros de la sociedad de una conciencia estética elevada (7). En dicha línea, 
debe sobresalir la intención de aumentar el placer estético como una vía mediante la cual los humanos no solo encuentren sosiego, sino, y sobre todo, impulsos y fuerzas para realizar tareas y vencer obstáculos.

4. En el plano estrictamente docente deben incrementarse las estrategias encaminadas al aumento del empleo creativo y sistemático de procedimientos que faciliten el contacto directo de los estudiantes con los objetos que poseen valores estéticos y artísticos (80), no solo para que desarrollen sus aptitudes o amplíen sus conocimientos, sino para que sean capaces de captar en ellos las fuerzas desalienantes y de mejoramiento humano.

5. Incentivar a los profesores de todas las especialidades a localizar en sus asignaturas los contenidos con potencial estético y a que los empleen transdisciplinariamente y de modo transversal, preferiblemente mediante trabajos independientes donde se empleen métodos activos que impulsen a los estudiantes a aplicar creativamente el saber y las habilidades que ya poseen y se transformen así en gestores y constructores de sus propios conocimientos y de su autoeducación, pero, sobre todo, de su crecimiento como seres humanos con la ampliación y enriquecimiento de su universo espiritual, con lo cual, a su vez, contribuyan al mejoramiento de compañeros y amigos y a la eliminación de tabúes, discriminaciones y otras fuerzas alienantes.

6. No absolutizar la utilización de los textos sobre arte y literatura porque, entre otras razones, no le gustan a todos los estudiantes. Con sensibilidad humana los profesores pueden romper tabúes, como la frialdad propia de la concepción positivista del conocimiento científico, y contribuir a que los alumnos abran sus sentimientos y desplieguen la sensibilidad humana.

7. Franquearle el camino a cuanto entiendan que son lados sensibles de los estudiantes. Pero, al mismo tiempo, hay otra arista importante del asunto y es el machismo. Los profesores y alumnos del sexo masculino tienen que entender que la sensibilidad (en todas sus variantes) es una propiedad humana y no solo del sexo femenino.

\section{Obras de arte y literatura - educación estética de la sensibilidad humana - humanismo}

Las obras de arte y literatura son el resultado de la actividad humana donde prevalecen los fines estéticos. Aunque la educación estética no se limita a ellas, es consustancial efectuar una orientación para que el educando las conozca, entienda, disfrute con el fin de contribuir al desarrollo de sus potencialidades creativas. En esta medida, la educación estética de la sensibilidad humana no puede desentenderse ni de las transformaciones de la producción artística y literaria, ni de los factores que las condicionan: no existe una norma universal para su creación y percepción; no prevalece entre los creadores el deseo de que exista tal regla; cada vez son más pálidas las fronteras entre las modalidades artísticas y entre ellas y lo no artístico, aunque se mantienen las especificidades dadas, ante todo, por el gesto y la capacidad de modificación. 
De la tríada creador-obra-consumidor, en la educación estética no se debe priorizar a los creadores, en cuanto estos, generalmente, despliegan su creatividad con códigos estéticos propios, y con frecuencia la realizan con una mínima o nula atención a las consideraciones externas. A su vez, debido a la descomunal velocidad con que se vive, a la pluralidad de gustos estéticos y a la rapidez con que cambian y desechan, resulta adecuado estimular "una vocación estética no lineal, abierta, en autoconstrucción permanente" (Sánchez Medina 31).

Hoy el valor de la educación estética crece cuando, mediante la flexibilidad y la apertura a lo nuevo, promueve "el desarrollo de una sensibilidad capaz de apreciar el significado estético no solo de las obras ya creadas y atenidas a los patrones normativos aceptados, sino también del arte innovador, transgresor, nuevo en cuanto a las propuestas estéticas que promueve" (Fabelo, "Aproximación teórica” 25). A veces lo innovador y lo transgresor propician beneficios a los humanos porque los enriquece espiritualmente con la estimulación de la imaginación y la fantasía, mediante las cuales, por ejemplo, puede mover sentimientos que lo llevan a pensar en el prójimo y en cómo remediar sus males, porque "la actitud estética no tiene por qué estar reñida con la actitud práctica" (Fabelo, "Por una estética" 96).

Las obras de arte y literatura tienen una potencia ideoestética que se entrelaza con las emociones y los sentimientos estéticos que despiertan; en ellos no pocas veces se hace sentir la asimilación práctico-espiritual que el creador ha hecho de su entorno natural o sociocultural, así como las transformaciones que impele, no exclusivamente rumbo a cambios sociales o políticos, sino al ensanchamiento del alma, como pretendía Novalis con su flor azul (Die blaue Blume), donde depositaba la fuerza enigmática del arte y su deseo de convertir el mundo en un lugar de belleza, a través del poder de la imaginación creativa y las proezas de los héroes. Con esta posición no se pretende que el creador sea un servidor humano, sino que con una obra de elevada calidad, que rebase los niveles alcanzados, sea capaz de mejorar humanamente a quienes la contactan, o bien impulsarlos a los quehaceres desalienantes.

Esa posición teórica no es una exageración de la función educativa de las obras de arte y literatura y de su poder liberador, más bien lo que hace es destacar la fuerza que tienen para despertar la sensibilidad humana y con ella la negación de la indiferencia. Dichas obras no solo producen placer estético, también favorecen "el crecimiento, el progreso, la dignificación, la emancipación del ser humano" (Fabelo, "Aproximación teórica" 21), condición que sale a relucir inmediatamente a la luz del humanismo. Mediante ellas es posible asimilar valores y conocer antivalores a través de los cuales se puede despertar el espíritu desalienante y de mejoramiento humano. La imagen artística, en cualquiera de sus manifestaciones, expone construcciones referentes a la vida e impulsa a que cada cual forme sus criterios, donde siempre hay una conjugación dialéctica de lo individual y lo social, debido a que entre el creador, la época y la sociedad, los nexos son fuertes y se evidencian incluso en la pretensión de aislarse de ellas. 
En cuanto a la educación estética de la sensibilidad humana, hay un aspecto que puede salir a relucir desde diversas perspectivas, pero que, cuando se observa mediante el prisma humanista, sobresale: hay personas que no se relacionan con dichas obras y necesitan una educación especial que despierte en ellos curiosidad, interés y los conduzcan a entender que su desconocimiento y su actitud son fuerzas opresoras que habría que destruir. Además, deben aprender a incorporar cualidades superiores, que no por obligación tienen que ser de índole moral, pues el mejoramiento humano no es solo de este tipo, también lo es cuando hay removimiento de las fibras espirituales. Al salir de un concierto o de una galería de arte, se puede sentir muchas cualidades activadas, como el amor y la bondad.

En el desarrollo de la educación estética es posible emplear todo tipo de obra, incluso la que se puede llegar a considerar pseudoarte, ya que lo importante es la crítica que incluye reconocer y destacar lo positivo y lo negativo, lo aprovechable y lo desechable. En todo este quehacer es central el énfasis en lo bello, pero no exclusivamente, pues no solo así se logra el enriquecimiento espiritual. Es significativo enfatizar la importancia de llegar a apreciar crítica y creativamente lo feo y la fealdad; no siempre son negativos; además, los aspectos no positivos de la vida también cuentan, solo que hay que saber apreciarlos y aprender a tratarlos debidamente.

Lo grotesco, lo sucio, lo repulsivo, cuando se plasma en una obra de arte o de literatura no por obligación es resultado de una extravagancia del creador, ni para estimular su difusión. Pero es necesario que el consumidor lo entienda, que sepa captar los mensajes y, más aun, que sea capaz de asumir una posición crítica. Esos son casos donde la educación estética de la sensibilidad humana puede y debe brillar. A los seres humanos hay que educarlos para que sepan contra qué luchar (no únicamente en el sentido político) y para que lo hagan; asimismo para que aprehendan crítica y creativamente lo que se les recomienda imitar. Esto también muestra el enriquecimiento del universo espiritual y reduce la indiferencia. Cuando la educación estética de la sensibilidad humana se observa desde el prisma del humanismo sobresale la necesidad de enfrentarse a las diversas manifestaciones de la alienación y de atender con esmero y creatividad el mejoramiento humano, que han de ser -valga la reiteración- perennes.

\section{Conclusiones}

La educación estética de la sensibilidad humana es humanista por naturaleza, porque su fin es la conjugación de los sentimientos y la razón en el universo estético para obtener respuestas y junto a ellas atacar la indiferencia y la pasividad. Esto lleva implícita la intención de mejoramiento humano; pero cuando se estudia desde la perspectiva del humanismo, sale a relucir, además, su esencia desalienante, que se manifiesta, de manera especial, en la oposición a la indiferencia como obstáculo al crecimiento humano. 
Este tipo de educación debe tener las siguientes características: realizarse de manera sistémica (es decir, que debe existir armonía entre sus principios, objetivos, estrategias y otros componentes); en ella debe prevalecer el espíritu de creatividad y optimismo; en su desarrollo emplear todo tipo de obra de arte y literatura para una crítica que pueda reconocer lo positivo y lo negativo, lo aprovechable y lo desechable. Todo esto puede efectuarse de muchas maneras, con amplitud y variedad de métodos. Pero en las escuelas es recomendable que se establezca una asignatura específica, organizada conscientemente y con la finalidad de luchar (desde la sensibilidad y el eje belleza-fealdad) contra las diversas manifestaciones de alienación que vayan apareciendo (como es la indiferencia) y por llevar el mejoramiento humano (guiado por el enriquecimiento del universo espiritual) a los niveles que exija la sociedad en el presente y el futuro más cercano.

\section{Referencias}

Arias, Rodrigo y Viviana Lemos. "Una aproximación teórica y empírica al constructo de inteligencia espiritual”. Enfoques 1 (2015): 79-102. Impreso.

Audi, Robert. Diccionario Akal de filosofía. Madrid: Akal, 2004. Impreso.

Bayer, Raymond. Historia de la Estética. La Habana: Pueblo y Educación, 1990. Impreso.

Beltrán, Vicente. Conversaciones esotéricas. <http://www.ngsm.org/vicenteba/libros2. htm>. Web. 3 Jun 2016.

Bodei, Remo. La forma de lo bello. Madrid: Visor, 1998. Impreso.

---. Geometría de las pasiones. México: Fondo de Cultura Económica, 1995. Impreso.

De la Fuente, Jorge. Estética. Selección de lecturas. La Habana: Félix Varela, 2001. Impreso.

Descartes, René. "Discurso sobre el método que ha de seguir la razón para buscar la verdad en las ciencias". Historia de la filosofía, tomo 3. La Habana: Félix Varela, 2011. Impreso.

Díaz, Santiago. Reflexión filosófica de la educación. Buenos Aires: Dirección general de cultura y educación, 2013. Impreso

Espinal, Claudia, Diego Estrada y Lina Pérez. "Una aproximación a la anorexia desde el discurso fenomenológico”. Revista Colombiana de Sociología 35.2 (2012): 183-193. Impreso.

Estévez, Pablo René. La educación estética: conceptos y contextos. La Habana: Pueblo y Educación, 2014. Impreso.

---. La alternativa estética en la educación. La Habana: Pueblo y Educación, 2014-b. Impreso.

Fabelo Corzo, José. "Aproximación teórica a la especificidad de los valores estéticos (I)". Graffylia 4 (2004): 17-25. Impreso.

---. "Por una estética apegada a la vida." Revista de Filosofía de la Universidad del Zulia 66 (2010): 89-100. Impreso. 
García, Gaspar. "El humanismo martiano". Simposio Internacional de Pensamiento Político y Antimperialista. Memorias. La Habana: Ciencias Sociales, 1989. Impreso.

Goleman, Daniel. Inteligencia emocional. Psikolibro, s. f. Web. 25 de enero de 2016.

Guadarrama, Pablo. "Humanismo y desalienación: un proyecto histórico inacabado". Humanismo, marxismo y postmodernidad. La Habana: Ciencias Sociales, 1998. Impreso.

Hegel, Georg Wilhelm Friedrich. De lo bello y sus formas. Buenos Aires: Austral, 1958. Impreso.

Jaeger, Werner. Paideia. Los ideales de la cultura griega. La Habana: Ciencias Sociales, 2010.

Lapoujade, María. Filosofía de la imaginación. México: Siglo xxI, 1988. Impreso.

Lardellier, Pascal. "El liberalismo a la conquista del amor." Revista de Sociología de la Universidad de Chile 29 (2014): 77-87. Impreso.

Larmin, Oleg. La educación estética en el socialismo desarrollado. La Habana: Arte y Literatura, 1984. Impreso.

Maldonado, Carlos. Visiones sobre la complejidad. Bogotá: El Bosque, 1999. Impreso.

Martins, Ernesto. "Os humanismos e a re-ligaçâo ao homen". Educaçâo e Filosofia 10.20 (1996): 93-113. Impreso.

Marx, Carlos. "Tesis sobre Feuerbach”. Obras Escogidas de Marx y Engels, tomo 1. Moscú: Progreso, 1973. Impreso.

Minkevicius, Yakev. "En busca de la definición íntegra del hombre". Problemas del mundo contemporáneo 115 (1988): 140-150. Impreso.

Montero, Graciela, et al. La educación estética del hombre nuevo. La Habana: Ciencias Sociales, 1987. Impreso.

Morin, Edgar. Los siete saberes necesarios para la educación del futuro. París: UNESCO, 1999. Impreso.

---. La cabeza bien puesta. Repensar la reforma. Reformar el pensamiento. Buenos Aires: Nueva Visión, 2002. Impreso.

Pupo, Rigoberto. Aprehensión martiana en Juan Marinello. La Habana: Academia, 1998. Impreso.

Rancière, Jacques. "Pensar entre las disciplinas: una estética del conocimiento". Inaesthetik (2008): 1-25. Impreso.

---. El malestar en la estética. Buenos Aires: Capital Intelectual, 2011.

Retana, Camilo. “Sociología de la moda”. Revista Mexicana de Sociología 2 (2014): 324-327.

Rodríguez, Pedro. Humanismo y Renacimiento. Madrid: Alianza Editorial, 1986. Impreso. Rousseau, Juan Jacobo. "Discurso sobre el origen de la desigualdad". Historia de la Filosofía, tomo 4. La Habana, Cuba: Félix Varela, 2011. Impreso.

Ruiz, Antonio. Humanismo y sobrehumanismo. Madrid, España: Aguilar, 1955. Impreso. Sánchez Vásquez, Adolfo. Las ideas estéticas de Marx. La Habana: Pueblo y Educación, 1990. Impreso. 
Sánchez Medina, Mayra. "Actualizaciones de axiología estética: vislumbrar la complejidad del mundo.” José Ramón Fabelo Corzo y Alicia Pino Rodríguez. Estética, arte y consumo. Su dinámica en la cultura contemporánea. Puebla/La Habana: Benemérita Universidad Autónoma de Puebla e Instituto de Filosofía de La Habana, 2011. Impreso.

Schiller, Federico. Educación artística (La educación estética del hombre). S. 1.: Tor, s.f. Impreso.

Silva, Electo. Educación estética y musical. Los coros infantiles. La Habana: Pueblo y Educación, 2001. Impreso.

Toffannin, Giuseppe. Historia del humanismo desde el siglo XIII hasta nuestros días. Buenos Aires, Argentina: Nova, 1953. Impreso.

Valdés, Gilberto. "Cultura y diversidad: las trampas del imaginario estético occidental”. Coord. José Ramón Fabelo Corzo y Alicia Pino Rodríguez. Estética, arte y consumo. Su dinámica en la cultura contemporánea. Puebla-La Hanaba: Benemérita Universidad Autónoma de Puebla/Instituto de Filosofía de La Habana, 2011. Impreso.

Varona Domínguez, Freddy. Humanismo, ideario de José Martí y pensamiento marxista cubano. La Habana: Félix Varela, 2013. Impreso.

Venegas, M. "Un modelo sociológico para investigar las relaciones afectivo-sexuales." Revista Mexicana de Sociología, 4 (2011): 559-589. Impreso.

Viegas Fernandes, João. “La educación que necesitamos” Temas 31 (2002): 4-17. Impreso.

Vitier, Cintio. "La espiritualidad de José Martí”. Anuario del Centro de Estudios Martianos 23 (2000): 100-130. Impreso.

Wagensber, Jorge. Ideas sobre la complejidad del mundo. Barcelona: Tusquets, 1998. Impreso.

Zambrano, María. Pensamiento y poesía en la vida española. México: Fondo de Cultura Económica, 1939. Impreso.

Recibido: 23 noviembre 2015

Aceptado: 05 septiembre 2016 